\title{
Serological Screening of Suspected COVID-19 Patients in Pakistan
}

\author{
Sajid $\mathrm{Ali}^{1}$, Anees Muhammad ${ }^{2}$, Tariq Mehar ${ }^{3}$, Najeeb ur Rehman ${ }^{4}$, Nourin Mehmood ${ }^{1}$ and Waseem Iqbal ${ }^{5}$ \\ ${ }^{1}$ Department of Biotechnology, Abdul Wali Khan University, Mardan, Pakistan \\ ${ }^{2}$ Department of Medical Lab Technology, CMT, Bacha Khan Medical College, Mardan, Pakistan \\ ${ }^{3}$ Medical B Ward, Hayatabad Medical Complex, Peshawar, Pakistan \\ ${ }^{4}$ Medical Ward, Fauji Foundation Hospital, Peshawar, Pakistan \\ ${ }^{5}$ Department of Pathology, Mardan Medical Complex, Mardan, Pakistan
}

\begin{abstract}
Objective: To determine the antibody levels (IgM and IgG), using ELISA in suspected patients of COVID-19.

Study Design: Descriptive cross-sectional study.

Place \& Duration of Study: Real Time PCR Diagnostic and Research Laboratory, Peshawar, Khyber Pakhtunkhwa, Pakistan, from May to July 2020.

Methodology: A total of 94 blood specimens were collected from suspected COVID-19 patients. The antibody levels (IgG and IgM) were determined, using a COVID-19 ELISA IgG and IgM kit.

Results: Out of a total 94 serum specimens, specimens were predominantly collected from males $(70.2 \%, n=66)$ as compared to females $(29.8 \%, n=28)$. Amongst six different age groups, the majority of the samples were found in the $31-45$ years, 16-30 years, and 46-60 years groups, $42.6 \%(n=40), 23.4 \%(n=22)$ and $22.3 \%(n=21)$, respectively. Of the 94 suspected COVID-19 patients' serum specimens, IgG and IgM were detected in $29.8 \%(n=28)$ and $39.4 \%(n=37)$, specimens, respectively. The IgG antibodies were detected more in males $(60.0 \%, n=18)$ than females $(40.0 \%, n=12)$ samples. Similarly, IgM antibodies were also found more frequently in males $(61.1 \%, n=22)$ as compared to females $(38.9 \%, n=14)$.

Conclusion: Detection of antibodies in COVID-19 infected patients provides vital clinical information for clinicians and could be used for the identification of suspected cases. Moreover, males were more prone to disease compared to females, and the 31-45 years age group was also more affected.
\end{abstract}

Key Words: Serological assays, IgG, IgM, Peshawar, Pakistan.

How to cite this article: Ali S, Muhammad A, Mehar T, Rehman NU, Mehmood N, Iqbal W. Serological Screening of Suspected COVID-19 Patients in Pakistan. J Coll Physicians Surg Pak 2021; 31(JCPSPCR):CR71-CR74.

\section{INTRODUCTION}

The coronavirus disease 2019 (COVID-19) first emerged in mid-December, 2019 in Wuhan, China. It severely affected human life and rapidly spread worldwide by trade and travel. ${ }^{1,2}$ Based on phylogeny and taxonomy, the causative agent of COVID-19 was categorised as a member of the coronavirus family and was named severe acute respiratory syndrome coronavirus 2 (SARS-CoV-2). ${ }^{2}$ SARS-CoV-2 may spread through bats and is capable of human-to-human transmission by various routes. ${ }^{3}$

Correspondence to: Anees Muhammad, Department of Medical Lab Technology, College of Medical Technology, Bacha Khan Medical College, Mardan, Pakistan

E-mail: aneesafridi15295@yahoo.com

Received: September 08, 2020; Revised: February 25, 2021; Accepted: March 08, 2021

DOI: https://doi.org/10.29271/jcpsp.2021.JCPSPCR.CR71
The signs and symptoms of COVID-19 infections overlap with other respiratory infections including pneumonia, tuberculosis, and asthma. ${ }^{4,5}$ The real-time reverse transcriptase-polymerase chain reaction (rRT-PCR) assay and radiological examinations are the currently available procedures for the detection and identification ofCOVID-19 patients. ${ }^{6}$ However, rRT-PCR andradiological examinations are not sufficient to screen a large number of patients, particularly in pandemic conditions. Therefore, specific diagnostic techniques are necessary to confirm suspected cases of COVID-19. ${ }^{7,8}$

The rRT-PCR assay is considered a gold standard for the diagnosis of COVID-19 infections. However, it is a time-consuming procedure and requires a biosafety level III laboratory, is labourintensive, and also needs well-trained technical staff. ${ }^{7.9}$ Moreover, due to the mass number of patients infected with COVID-19, the availability of the rRT-PCR assay is limited. Furthermore, lack of the site of specimen collection, lack oftechnical staff, and disease incubation period significantly affect the specificity and sensitivity of the rRT-PCR assay in the diagnosis of COVID-19. ${ }^{10}$ 


\begin{tabular}{|c|c|c|c|c|c|}
\hline \multirow{2}{*}{\multicolumn{2}{|c|}{ Age }} & IgG & \multirow{2}{*}{$\begin{array}{l}\text { Total } \\
\%(n)\end{array}$} & $\lg M$ & \multirow{2}{*}{$\begin{array}{l}\text { Total } \\
\%(n)\end{array}$} \\
\hline & & $\begin{array}{c}\text { Positive } \\
\%(n)\end{array}$ & & $\begin{array}{c}\text { Positive } \\
\%(n)\end{array}$ & \\
\hline \multicolumn{2}{|l|}{$0-15$} & $1.1(1)$ & $1.1(1)$ & $0(0)$ & $1.1(1)$ \\
\hline \multicolumn{2}{|l|}{$16-30$} & $4.3(4)$ & $23.4(22)$ & $5.3(5)$ & $23.4(22)$ \\
\hline \multicolumn{2}{|l|}{$31-45$} & $10.6(10)$ & $42.6(40)$ & $16.0(15)$ & $42.6(40)$ \\
\hline \multicolumn{2}{|l|}{$46-60$} & $12.8(12)$ & $22.3(21)$ & $13.8(13)$ & $22.3(21)$ \\
\hline \multicolumn{2}{|l|}{$61-75$} & $3.2(3)$ & $8.5(8)$ & $3.2(3)$ & $8.5(8)$ \\
\hline \multicolumn{2}{|l|}{$>75$} & $0(0)$ & $2.1(2)$ & $0(0)$ & $2.1(2)$ \\
\hline \multirow{2}{*}{ Gender } & Female & $40.0(12)$ & $29.8(28)$ & $38.9(14)$ & $29.8(28)$ \\
\hline & Male & $60.0(18)$ & $70.2(66)$ & $61.1(22)$ & $70.2(66)$ \\
\hline \multicolumn{2}{|l|}{ Total } & $100(30)$ & $100(94)$ & $100(36)$ & $100(94)$ \\
\hline
\end{tabular}

Therefore, a simple, easy to use, and accurate diagnostic procedure is needed to improve the diagnosis and outcome of COVID-19. The serological tests have been developed to detect antibodies against the SARS-CoV-2 for the diagnosis of COVID-19. ${ }^{11,12}$ Serological testing such as the ELISA technique is appropriate for screening, surveillance and epidemiological purpose; whereas, rRT-PCR for clinical diagnosis purposes. ${ }^{13,14}$

After COVID-19 infection, immunoglobulin M (IgM) antibodies developed in patients as an immune response, which may indicate a new or current infection in the patients. ${ }^{14}$ Then, immunoglobulin G (IgG) antibodies developed, which indicates the recovery period of the infection. ${ }^{15,16}$ Therefore, both IgM and IgG antibody tests provide information about the period of infections and are important for timely treatment. $^{13}$

To date, there has been no study conducted in the studied region regarding antibody testing. Therefore, this study aimed to determine the antibodies (IgM and IgG) levels in suspected cases of COVID-19 patients in Khyber Pakhtunkhwa, Pakistan.

\section{METHODOLOGY}

This cross-sectional study was conducted over 3 months from May to July 2020 in the Real Time PCR Diagnostic and Research Laboratory, Peshawar, Khyber Pakhtunkhwa, Pakistan. All suspected COVID-19 patients were included irrespective of age, gender, ethnicity, and duration of infection.

Ninety-four blood samples were collected from suspected COVID-19 patients. The serum from the blood samples was separated by centrifugation for 10 minutes at 3,000 rpm. The antibodies (IgG and IgM) against the SARS-CoV-2 specific antigens nucleocapsid protein (N-Protein) and spike glycoprotein (S-protein) were determined using the COVID ELISA kit manufactured by Vircell (Reference MA1032, COVID-19 ELISA IgG and IgM+lgA) (http://en.vircell.com/products/covid-19-elisa/).

This study was approved by the Ethical Committee of the Department of Biotechnology, Abdul Wali Khan University,
Mardan. Verbal consent was obtained from all the participants. The statistical package for Social Science version 22 (SPSS-22) was used for further data analysis. The mean and standard deviation were noted for quantitative data, while frequencies and percentages for qualitative data. Various cross-tabulation analyses were designed using the SPSS- 22 .

\section{RESULTS}

A total of 94 samples were collected from suspected COVID-19 patients having a mean age of $41.8 \pm 15.6$ years. Of the 94 samples, $29.8 \%(n=28)$ were from females, mean age $41.4 \pm 14.7$ years; and $70.2 \%(n=66)$ were from males, mean age $41.9 \pm 16.1$ years. The majority of the samples were obtained from the 31-45 year age group $(42.6 \%, n=$ $40)$, followed by age group $16-30$ years $(23.4 \%, n=22)$, age group $46-60$ years $(22.3 \%, n=21)$, and age group greater than 75 years $(2.1 \%, n=2)$, while the $0-15$ years age group had the fewest samples $(1.1 \%, n=1)$.

All samples were tested for both IgG and IgM antibodies. The IgG antibodies were found more frequently in the 46-60 years age group $(12.8 \%, n=12)$; whereas, the lowest were found in the age group $0-15$ years $(1.1 \%, n=1)$. No IgG antibodies were detected in the $>75$ age group. Similarly, in the IgM antibody test, the highest proportion of samples positive for IgM antibodies were noted in the 31-45 years group $(16.0 \%, n=15)$, while $\lg M$ antibodies were not detected in the $0-15$ years and $>75$ years age groups (Table I).

The presence of IgG and IgM antibodies was assessed in all suspected COVID-19 patients, using the Vircell ELISA kit. Of the 94 patients, IgG antibodies were detected in $31.9 \%$ $(n=30)$, with $40 \%$ and $60 \%$ being in female and male patients, respectively. Similarly, IgM antibodies were identified in $38.3 \%(n=36)$ of patients. IgM was $38.9 \%$ positive in female patients, and $61.1 \%$ were found in male patients (Table I).

Amongst 94 suspected COVID-19 patients, the overall IgM antibodies $(38.3 \%, \mathrm{n}=36)$ were detected more than IgG antibodies $(31.9 \%, n=30)$, and both IgG and IgM were detected in $27.7 \%(n=26)$ patients. 


\section{DISCUSSION}

The detection of specific antibodies (IgM and IgG against SARS-CoV-2 $\mathrm{N}$ and S proteins) is helpful to assess suspected COVID-19 patients; and for epidemiology and surveillance studies. The current ELISA results show the highest number of patients positive for either IgG or IgM were more frequently identified in the younger population and males compared to children, older people, and females. Similar to the current study, another report showed that males were more frequently infected than female patients $(68 \%(n=34)$ vs. $32 \%(n=16)$, respectively) ${ }^{17}$ Consistently, a report showed that males $(78.9 \%, n=15 / 19)$ were more frequently infected than females $(21.1 \%, n=4 / 19) .{ }^{18}$ There are several potential factors that explain that males are more vulnerable than females including environmental exposure, weak immune system, angiotensin-converting enzyme 2 (ACE2), and the transmembrane protease, serine 2 (TMPRSS2). ACE-2 and TMPRSS2 are both the receptor for attachment of COVID-19 virus. ${ }^{19}$

In this study, IgG and IgM antibodies were found in $31.9 \%$ and $38.3 \%$ individuals, respectively. Both IgG and IgM antibodies were detected in the blood serum of $27.7 \%$ of participants. The sensitivity and specificity of serological tests by ELISA in China and the United States was $38.3 \%-85.4 \%$ in hospitalised patients. ${ }^{13,17}$ This inconsistency is likely to be due to the variation in clinical setups in different countries and the technique used in these settings. A study revealed $10 \%(5 / 50)$ and $14 \%(7 / 50)$ positivity of IgG and IgM antibodies, respectively, in RT-PCR confirmed patients. ${ }^{17}$ Spicuzza et al., reported $82.6 \%$ (19/23) of both IgG and IgM in confirmed COVID-19 patients. ${ }^{20}$ The greater inconsistency with the current study might be due to the population of confirmed COVID-19 patients studied and the smaller sample size.

It is essential to evaluate the asymptomatic and confirmed COVID-19 infected patients through antibody testing. It is important to confirm the results of the present study with greater sample size, different techniques, and population to determine the importance of ELISA-based antibody testing for screening and diagnostic purposes. Moreover, there is still some conflict regarding the serological tests for COVID-19 due to the presence of antibodies before, during, and after the onset of symptoms. Despite these limitations, consistency was found with many other relevant studies conducted in different regions of the world.

Based on the present study findings, antibody tests are rapid, reliable, have high sensitivity, and will be helpful for screening a large population. In patients where there is a discrepancy between clinical findings, radiological examinations, and molecular diagnostic testing, antibody detection might be useful for clinicians to reach the correct diagnosis and in the management of patients.

\section{CONCLUSION}

The findings of the current study help provide information regarding the rapid screening of COVID-19 infected patients through serological testing (ELISA). Overall, the sensitivity of the serological ELISA assay is lower, but these results suggest that the serological tests are useful in the screening and detection of COVID-19 patients.

\section{CONFLICT OF INTEREST:}

The authors declared no conflict of interest.

\section{AUTHORS' CONTRIBUTION:}

SA: Study design, literature review, data analysis, interpretation, and final approval.

AM: Study design, literature review, data analysis, interpretation, and write-up.

TM: Literature review, manuscript writing, draft formation, and final approval.

NBR: Study design, data analysis, interpretation, finalising draft, and final approval.

NM, WI: Study design, finalising and approval of draft and data collection.

\section{REFERENCES}

1. WHO statement (2020). "Statement on the second meeting of the International Health Regulations (2005) Emergency Commit- tee regarding the outbreak of novel coronavirus (2019-nCoV)". World Health Organization. 31 January 2020. Retrieved 6 February 2020; Available from: http:// www.who.int/news-room/detail/30-01-2020- statement- onthe- second- meeting- of- the- international- health- regulations- (2005)-emergency-committee-regarding-the-outbreak-of-novel-coronavirus-(2019-ncov).

2. Zhu N, Zhang D, Wang W, Li X, Yang B, Song J, et al. A novel coronavirus from patients with pneumonia in China, 2019. New England J Med 2020; 382(8):727-33. doi: 10.1056/NEJMoa2001017.

3. Wu Y, Ho W, Huang Y, Jin DY, Li S, Liu SL, et al. SARS-CoV-2 is an appropriate name for the new coronavirus. Lancet 2020; 395(10228):949-50. doi: 10.1016/S0140-6736(20) 30557-2.

4. Yang $X, Y u Y, X u J$, Shu $H$, Liu H, Wu Y, et al. Clinical course and outcomes of critically ill patients with SARS-CoV-2 pneumonia in Wuhan, China: A single-centered, retrospective, observational study. Lancet Respir Med 2020; 8(5):475-81. doi: 10.1016/S2213-2600(20)30079-5.

5. Chen N, Zhou M, Dong X, Qu J, Gong F, Han Y, et al. Epidemiological and clinical characteristics of 99 cases of 2019 novel coronavirus pneumonia in Wuhan, China: A descriptive study. Lancet 2020; 395(10223):507-13. doi: 10.1016/S0140-6736(20)30211-7.

6. Shahzeb M, Khan A, Muhammad A. Detection of coronavirus disease (COVID-19) using radiological examinations. J Pure Appl Microbiol. 2020; 14(suppl 1): 911-20. doi.org/10. 22207/JPAM.14.SPL1.28

7. Corman VM, Landt O, Kaiser M, Molenkamp R, Meijer A, Chu DK, et al. Detection of 2019 novel coronavirus (2019-nCoV) 
by real-time RT-PCR. Eurosurveillance 2020; 25(3): 2000045. doi: 10.2807/1560-7917.ES. 2020.25.3.2000045.

8. Chu DK, Pan Y, Cheng SM, Hui KP, Krishnan P, Liu Y, et al. Molecular diagnosis of a novel coronavirus (2019-nCoV) causing an outbreak of pneumonia. Clinical Chemistry 2020; 66(4):549-55. doi: 10.1093/clinchem/hvaa029.

9. Klein D. Quantification using real-time PCR technology: Applications and limitations. Trends Molecular Medicine 2002; 8(6):257-60. doi: 10.1016/s1471-4914(02)02355-9.

10. Wu JL, Tseng WP, Lin CH, Lee TF, Chung MY, Huang $\mathrm{CH}$, et al. Four point-of-care lateral flow immunoassays for diagnosis of COVID-19 and for assessing dynamics of antibody responses to SARS-CoV-2. J Infection 2020; 81(3):435-42. doi: 10.1016/j.jinf.2020.06.023.

11. Lassaunière R, Frische A, Harboe ZB, Nielsen AC, Fomsgaard A, Krogfelt KA, et al. Evaluation of nine commercial SARS-CoV-2 immunoassays. Medrxiv 2020; doi.org/ 10.1101/2020.04.09.20056325.

12. Whitman JD, Hiatt J, Mowery CT, Shy BR, Yu R, Yamamoto TN, et al. Test performance evaluation of SARS-CoV-2 serological assays. Nature Biotechnol 2020; 38(10): 1174-1183. doi: 10.1101/2020.04.25.20074856.

13. Li Z, Yi Y, Luo X, Xiong N, Liu Y, Li S, et al. Development and clinical application of a rapid IgM-IgG combined antibody test for SARS-CoV-2 infection diagnosis. J Med Virol 2020; 92(9):1518-1524. doi: 10.1002/jmv.25727.

14. Liu R, Liu X, Han H, Shereen MA, Niu Z, Li D, et al. The comparative superiority of IgM-IgG antibody test to real-time reverse transcriptase PCR detection for SARS-CoV-2 infection diagnosis. MedRxiv 2020; doi.org/10.1101/ 2020.03.28.20045765.

15. Zhu M. SARS immunity and vaccination. Cell Mol Immunol 2004; 1(3):193-8.

16. Li G, Fan Y, Lai Y, Han T, Li Z, Zhou P, et al. Coronavirus infections and immune responses. J Medical Virol 2020; 92(4):424-32. doi: 10.1002/jmv.25685.

17. Cassaniti I, Novazzi F, Giardina F, Salinaro F, Sachs M, Perlini S, et al. Performance of VivaDiag COVID-19 IgM/lgG Rapid Test is inadequate for diagnosis of COVID-19 in acute patients referring to emergency room department. J Med Virol 2020; 92(10):1724-7. doi: 10.1002/jmv.25800.

18. Padoan A, Sciacovelli L, Basso D, Negrini D, Zuin S, Cosma $C$, et al. IgA-Ab response to spike glycoprotein of SARS-CoV-2 in patients with COVID-19: A longitudinal study. Clinica Chimica Acta 2020; 507:164-6. doi: 10.1016/ j.cca.2020.04.026.

19. Penna C, Mercurio V, Tocchetti CG, Pagliaro P. Sex-related differences in COVID-19 lethality. British J Pharmacol 2020; 177(19):4375-85. doi: 10.1111/bph.15207.

20. Spicuzza L, Montineri A, Manuele R, Crimi C, Pistorio MP, Campisi $R$, et al. Reliability and usefulness of a rapid IgMIgG antibody test for the diagnosis of SARS-CoV-2 infection: A preliminary report. J Infection 2020; 81(2):e53-e4. doi: 10.1016/j.jinf.2020.04.022. 